КОМАРОВСКИЙ Владимир Савельевич - доктор философских наук, профессор Института государственной служббы и управления Российской академии народного хозяйства и государственной службы при Президенте РФ (119571, Россия, г. Москва, пр-кт Вернадского, 84; poiginalb@yandex. ги); заслуженный деятель науки РФ

\title{
ВИДЕНИЕ БУДУЩЕГО СТРАНЫ РОССИЙСКОЙ МОЛОДЕЖЬЮ: НАДЕЖДЫ И ОПАСЕНИЯ
}

\begin{abstract}
Аннотация. В статье на основе данных социологического исследования анализируется представление студентов о желаемом образе страны в исторически обозримой перспективе 20-25 лет. Выясняется, что необходимо, по их мнению, изменить в стране, чтобы она смогла адекватно отвечать на вызовы современности и занять достойное место в числе самых передовых стран мира, стать привлекательной для молодежи. Автор анализирует готовность молодежи принять личное участие в построении лучшего будущего, идентифицировать себя со страной (или, наоборот, покинуть ее при первом удобном случае), роль образа будущего страны как консолидирующего общество (конфликтогенного) фактора.
\end{abstract}

Ключевые слова: образ будущего, молодежь, ценности, идентичность, консолидация, конфликт

$\mathrm{K}^{\mathrm{a}}$ ак отмечают ряд авторитетных исследователей (например, И. Семененко), тема будущего стала в настоящее время одним из мейнстримных направлений исследований в политической науке и социологии, особенно в странах, переживающих процесс институциональных трансформаций, выбора стратегических целей и моделей национального развития, национально-государственной идентичности, - странам, к которым относится и Россия [Семененко 2021].

О важности решения этих вопросов свидетельствует такой факт: в 2008 г. комиссия по экономическому росту и сотрудничеству Всемирного банка обобщила опыт модернизации 13 наиболее успешных стран. Выяснилось, что при всех различиях им присуще и немало общего. Наряду с экономическими показателями, эти страны отличаются от менее успешных (или совсем неуспешных) наличием национального консенсуса по поводу долгосрочных целей развития. Другими словами, консенсуса по кардинальным вопросам: куда идем, какую страну строим, какими методами, каким видим будущее страны.

В основе целеполагания, определяющего выбор социально значимых приоритетов и эффективность взаимодействия институтов государства и граждан, лежат ценности доверия, ответственности, социальной солидарности. Эти ценности имеют ключевое значение для консолидации общества на основе неконфликтного согласования их интересов [Семененко 2021: 25].

Ключевой актор выбора цели в России - политическое руководство страны. Вместе с тем этот выбор, безусловно, должен отвечать и на запросы общества. Как показывают многочисленные исследования, в настоящее время запрос на стабильность сменился в обществе запросом на перемены и социальную справедливость, российский вариант обшества всеобшего благосостояния Западной Европы с тем отличием, что из ценностей демократии по-настоящему востребована лишь одна - равенство всех и вся перед законом. Утверждение в жизнь запроса на равенство перед законом уже само по себе снижает конфликтогенный потенциал общества, поскольку предполагает создание общепризнанного механизма разрешения конфликтов. Утверждение принципов социальной справедливости способствует утверждению социальной солидарности и также снижает конфликтогенный потенциал в обществе, создает условия для выработки и утверждения консенсуса относительно долгосрочных целей развития страны, а в дальнейшем - и национально-государственной идентификации. 
Из сказанного выше вытекает главная цель данной статьи: выявить консолидирующий и(или) конфликтогенный потенциал образа будущего страны и молодежи как применительно к самой молодежи, так и к ее отношению к стране, единению с ней, формированию национально-государственной идентичности.

В основе статьи лежит анализ данных эмпирического исследования, осуществленного методом фокус-группового интервью под руководством автора в 2019 г. в 10 вузах страны, расположенных в различных регионах - городах страны (от Владивостока до Калининграда). В 4 из них в ноябре-декабре 2020 г. были проведены повторные исследования.

Воспроизведем главные теоретико-методологические положения исследования, как они видятся автору на сегодняшний день [Комаровский 2020; Образ будущего России... 2021]. Образ страны включает образ территории (природа, экономика, социальная сфера), образ народа, проживающего на этой территории, образ власти, образ лидера, миссию страны и ее роль на международной арене.

Вторая ипостась анализа образа будущего страны - его согласованность и целостность политики: цель, средства, акторы, результат.

Образ будущего является важным фактором формирования у молодежи национально-государственной, общероссийской идентичности, он во многом задает ориентиры ее устремлений и действий в политической и иных сферах жизни, вплоть до желания эмигрировать в другую страну. Одновременно отсутствие ясных и четких перспектив будущего дезориентируют молодых граждан, сужает временной диапазон планирования ими тех целей и перспектив, которых они хотели бы достигнуть, не позволяет предметно соотнести собственные цели и перспективы развития страны.

\section{Анализ результатов исследования}

Первый вопрос, на который автор хотел получить ответ в ходе исследований, был следующим: значима ли проблема будущего страны для молодежи и в каком - позитивном или негативном - виде она им представляется. На первую часть вопроса ответ получен однозначный - значима. В ходе дискуссий при обсуждении поставленного модератором вопроса: «Как вы представляете будущее России через 20-25 лет, что в ней должно измениться, чтобы вы с уверенностью могли сказать: это моя страна, мне в ней достойно и комфортно жить?» - было выявлено, что абсолютное большинство студентов независимо от места проживания не живут исключительно сегодняшним днем, своими личными заботами и проблемами. Они задумываются о будущем страны и что ее ждет в перспективе. Фактически не было лиц, которые не смогли ответить на заданный вопрос или заявить, что будущее страны им безразлично. Одновременно многие студенты заявляли, что страна фактически живет сегодняшним днем, о чем свидетельствует, по их мнению, прежде всего положение в экономике - она как была, так и остается в своей основе сырьевой, топчется на месте, а экология неуклонно ухудшается. Многие студенты заявляли, что Россия все больше отстает от передовых и даже развивающихся стран: «Если все будет как сейчас, то через 20-25 лет Россия не выдержит конкуренции с другими странами, такими как Китай или даже Индия» (студент Ярославского государственного университета им. П.Р. Демидова).

Итак, резюмируем: потенциально образ будущего страны может быть интегрирующим молодежь со страной фактором, но здесь неизбежно возникают сомнения, что он таковым является де-факто, поскольку реальный образ страны у студентов содержит мало положительных констатаций. В целом, по 
нашим данным, хотя Россия в представлениях студентов «встала с колен», но в ней столько нерешенных проблем (коррупция, социальная незащищенность, произвол властей и т.д., и т.п.), что многим из них нередко становится стыдно за страну.

Если для населения в целом образ России в настоящее время выглядит скорее привлекательным, чем непривлекательным [Шестопал 2019: 445], то у студентов скорее наоборот. Следует ли из этого, что такой образ страны означает отсутствие стержня для консолидации молодежи со страной, формирования единой общероссийской идентичности? Однозначного ответа на этот вопрос нет.

Некоторые специалисты заявляют, что Россия - генетически несовременная страна, такой она была, есть и будет, хотя у нее и довольно прочная конструкция [Иноземцев 2018]. Студенты с этими утверждениями не согласны. Большинство из них настроены на перемены, ждут перемен, верят, хотя и с оговорками, в их успех, верят в будущее России. О настрое на перемены ярче всего высказалась студентка из Владивостока (2020 г.): «Как бы мы ни были настроены воспринимать происходящее - оптимистично или пессимистично, - с каждым днем все сильнее ощущается приближение перемен, которые затронули практически все стороны общественно-политической жизни».

При этом, по мнению большего числа студентов и цитируемого автора, перемены должны носить кардинальный характер, затрагивать «основы внутренней жизни страны, иначе этой страны просто не будет» (Краснодар, 2020). Другой студент из этой же группы отмечает, что народ (точнее, молодежь) обладает необходимыми ресурсами и желанием для кардинальных перемен. «Я считаю, что у нашей страны есть огромные ресурсы, огромные возможности для того, чтобы стать одной из самых сильных держав и действительно преуспевать во многих случаях. Через 20-25 лет молодежь будет кардинально менять страну и уже начинает менять ее».

Констатируем: отношение к стране студентов определяется в первую очередь не тем, как она выглядит в их глазах в настоящее время (сегодня), а тем, какой она может стать, по их мнению, в будущем. Может ли она стать успешной, современной страной в полном смысле этого слова или нет. Здесь проходит водораздел в студенческой среде - между теми, кто верит в успех страны, и теми, кто скорее разделяет точку зрения В. Иноземцева. Большинство студентов верят, хотя и с оговорками, в успешное развитие страны в предстоящие десятилетия, поэтому образ будущего России в их сознании можно квалифицировать как условно позитивный (при этом с общей, даже условно позитивной оценкой будущего России согласны не все студенты - часть из них вообще ставят под сомнение будущность страны). Более того, среди студентов с условно позитивным представлением о будущем России наблюдается существенное расхождения по большинству других аспектов будушего страны. Дискуссия, возникающая входе фокус-группового интервью, не способна преодолеть разногласия участников. В большинстве случаев каждый оставался при своем мнении, что, на наш взгляд, свидетельствует о глубине различий.

Единого мнения о будущем страны нет даже среди студентов одной группы. Это свидетельствует о слабости консолидирующего потенциала образа будущего страны.

Ослабляет консолидирующий потенциал образа страны у студентов и его содержательная противоречивость, неполнота и незавершенность образа, что отмечается не только у обычных граждан [Шестопал 2019], но и среди студентов. Более обстоятельную информацию по затронутым вопросам автор стремился получить, выясняя мнение студентов о том, что надо менять в стране, 
как надо менять, кто может быть главным актором перемен. С этой целью рассмотрим подробнее, как студенты представляют себе содержание тех перемен, которые, по их мнению, необходимы (назрели) в стране.

Нереалистично ожидать, что студенты смогут охарактеризовать весь комплекс проблем, стоящих перед нынешней Россией, которые необходимо решить в ближайшее десятилетие. Как правило, они или оценивают ситуацию в целом («надо менять все», «надо менять внутреннюю политику»), или, значительно чаще, указывают на приоритетные направления желаемых изменений.

Наивным также было бы ожидать, что, говоря о кардинальных изменениях существующего строя, студенты способны предложить программу этих изменений. Лишь в отдельных случаях в их ответах можно обнаружить зачатки, отдельные фрагменты таких программ, связанных, как правило, с переустройством общества на социалистических началах. Чаще всего под кардинальными изменениями они имеют в виду смену власти и курса («нужно поменять президента и правительство и дать молодежи больше власти в управлении страной»), формирование в стране реального социального государства (как в Финляндии или Дании) и смену моделей экономического развития, преодоление сырьевой направленности экономики, формирование современной экономики знаний.

«Смена правительства - только так можно добиться изменений в стране. Естественно, молодежь тоже должна принимать в этом участие» (Уфа). «Для начала нужно поменять сам процесс управления, Государственную думу, кабинет министров» (Москва). В качестве актора этих перемен и в 2019, и в 2020 г. большинство студентов видят прежде всего самих себя, молодежь в целом, но не власть или старшие поколения «одурманенные телевизионной пропагандой и неспособные на решительные перемены» (Махачкала, 2019). Одновременно со всей определенностью подчеркнем, что «решительные действия» в представлениях студентов не связаны с революционными потрясениями. Пока не связаны.

В случае углубления кризисных явлений, вызванных COVID-19 или другими факторами, в т.ч. политическими, связанными, в частности, с предстоящими в 2021 и 2024 гг. выборами, ситуация может резко измениться. Гарантий, что требования молодежью перемен не приобретут более радикальный характер, нет, тем более что идентифицировать себя, свою будущность со страной, такой как она есть, на сегодня многие студенты в принципе не готовы. Тем более что в 2020 г. в сравнении с 2019 г. резче стали звучать требования политических перемен.

Критики в адрес существующей политической системы, президента и правительства больше не стало, но заметно изменилась ее направленность. В центре - сменяемость власти и честные выборы. «Обязательно нужно обеспечить сменяемость власти и честные выборы, тогда через 20-25 лет Россия может сильно преобразиться» (Владивосток). «Если у нас демократическая страна, значит должен быть демократический строй в прямом смысле этого слова. Те же самые выборы» (Краснодар). «Надо сейчас обеспечить сменяемость кадров, многие из них сильно задерживаются на своих местах и не дают дорогу молодым. У них (молодых) исчезает мотивация» (Краснодар). «Сменяемость власти необходима еще и потому, что выросло «новое поколение, имеющее иные взгляды на страну. Они имеют право их отстаивать и воплощать в жизнь потому, что именно им жить и обустраивать эту страну» (Владивосток). На наш взгляд, это самые серьезные заявления, дающие ключ к пониманию многих процессов, связанных с молодежью, происходящих не только в России, но и в других странах постсоветского пространства.

Если характеризовать ситуацию в целом в интересующем нас плане, есть 
основания утверждать, что образ будущего страны в сознании студентов несет в себе немалый конфликтогенный потенциал как по линии «молодежь старшие поколения», так и по линии «молодежь - власть». Совершенно очевидно, что протестные выступления молодежи в стране возникают не на пустом месте. За ними в т.ч. стоят разные представления о будущем страны и роли в этом будущем другого, молодого поколения. «В любом государстве молодежь диктует общественные потребности, и поэтому государство обязано прислушиваться к мнению молодежи, ...если этого не происходит, возникает извечная проблема “отцов и детей”... что приводит в итоге к несогласию молодежи с политикой государства, а отсюда “великая депрессия” у молодежи» (Краснодар, 2019 г.).

Истоки «великой депрессии» молодежи, порождающие, в конечном счете, конфликтогенный потенциал, состоят не только в том, что, по мнению значительной части студентов, власть не уделяет должного внимания решению молодежных проблем (не создает социальные лифты для карьерного продвижения молодежи, возможности для самореализации и даже откровенного обмена мнениями и т.д.) [Образ будущего...2021: 88-107], но и в том, что в стране сложился несправедливый механизм распределения национального богатства, достигнут критический уровень социального неравенства. При этом некоторые студенты отмечают, что существующая система распределения доходов не только несправедлива, но и является тормозом развития страны: богатые тратят огромные деньги на предметы роскоши или вывозят их за границу вместо того, чтобы вкладывать в производство и обновление инфраструктуры (Ярославль). Правительство же предпочитает уходить от решения этой проблемы.

Если сравнить желаемый образ будущего молодежи и населения в целом, особенно в ретроспективе, то, наряду с совпадениями, нельзя не отметить и существенные различия. Научный руководитель факультета политологии и социологии Финансового университета при Правительстве РФ В.В. Федоров 27.09.2013 г. опубликовал в «Независимой газете» статью «Демократия по-российски - справедливость, а не конкуренция», из которой следует, что общественный идеал современных россиян таков: независимое и влиятельное, авторитетное в мире государство; высокоразвитая держава с высоким уровнем жизни, конкурентоспособной наукой и промышленностью; многонациональная страна, где русский народ играет особую центральную роль, но уважаются и защищаются права всех национальностей; страна с сильной центральной властью, возглавляемая президентом с широкими полномочиями. Это страна, где торжествует закон и все перед ним равны. Страна восстановленной справедливости в отношениях людей друг с другом и с государством. Таким образом, делает вывод автор, государство с сильным лидером, дрейфующее в сторону социализма, обеспечивающее высокий уровень жизни и социальную защиту, желаемый идеал для большинства населения.

Сравнивая предложенные образы желаемого будущего нетрудно убедиться, что для современной молодежи общество во главе с заботливым и требовательным лидером, президентом-отцом, умным автократом - вовсе не идеал и далеко не главная основа его политического устройства. Залог успехов страны в будущем, по мнению студентов, скорее в другом - в выходе на авансцену политической и общественной жизни страны нового поколения со своим видением мира, идеалами и ценностями. Именно расхождение в ценностях формирует представления о других принципах политического устройства страны в будущем, что, в свою очередь, рождает потенциал конфликтного отношения к настоящему и к тем, кто его олицетворяет.

Из сказанного выше логично возникает следующий вопрос: готова ли рос- 
сийская молодежь к реальной деятельности и борьбе за переустройство страны в соответствии с ее видением будущего? Как справедливо отмечает профессор А.И. Соловьев, одних благих намерений мало. Молодые люди должны понимать, что повестка дня (ближайшее будущее, равно как и отдаленное, заметим от себя) складывается в результате не благих намерений, а жесткой конкуренции. Перед молодежью как активным участником приближения будущего стоит задача трезвой оценки своего политико-административного статуса, понимания реальных возможностей включения в конкурентную борьбу с ведущими политическими игроками за цели общественного развития. Это является условием ее участия в формировании образа «желаемого будущего» [Образ будущего... 2021: 137].

Данные, полученные в ходе исследования на этот счет, противоречивы. В ходе анализа дискуссии по вопросам: «Что необходимо предпринять, чтобы желаемое будушее стало реальностью, и что для этого может сделать молодежь?» - в 2019 г. были выявлены две полярные позиции: ориентация на собственные усилия людей, молодежи в первую очередь («чтобы изменить будущее страны каждый человек должен начать с себя», «думать не только о себе и своей выгоде, но и об общих интересах», «привыкать к здоровому образу жизни», Уфа; «больше участвовать в жизни страны», Мичуринск) и ориентация на усилия властных структур государства («если власти не будут пытаться что-то делать, то ничего не изменится», Мичуринск). Промежуточная позиция - объединение усилий власти и общества (молодежи) ради построения достойного будущего - в высказываниях студентов тоже присутствует, но выражена менее ярко. Все три позиции могут быть представлены в одной и той же группе студентов, и, как и в предыдущем случае, переубедить друг друга в ходе дискуссии они не могут (о чем, в частности, свидетельствуют приведенные выше примеры высказываний студентов из Мичуринска). Исследование 2020 г. не выявило заметных различий в сравнении с 2019 г. Дополнительно отвечая на прямой вопрос: «Какова роль молодежи в будущем переустройстве России, и что конкретно она может для этого сделать?» - немалая часть молодежи заявляла - «ничего». Их точку зрения в 2019 г. лаконично выразил студент из Мичуринска: «Молодежь для этого (изменить будущее страны в лучшую сторону) ничего не может сделать. Правительство будет ориентироваться на тех, у кого больше денег. Обычные люди ничего не смогут изменить». «Молодежь ничего не сможет сделать потому, что ее инициативы, за отдельным исключением, не воспринимаются властью (особенно на местах), власть не терпит критики, вплоть до преследования “критиканов”; люди не могут открыто выражать свои мысли... Можно сесть в тюрьму за репост» (Красноярск).

Спектр называемых трудностей и препятствий для проявления активности молодежи в представлениях студентов весьма широк: это и неразвитость в стране гражданского общества, и малочисленность специальных программ, направленных на повышение социальной активности молодежи, и узость социальных лифтов для движения по карьерной лестнице («нет свободного перемещения в социальных лифтах», Краснодар, 2020; «необходимо омолодить власть за счет молодых политически деятельных людей», Владивосток, 2020). Примерно такая же часть обследованной студенческой молодежи видит проблемы не в позиции властей или «объективных обстоятельствах», а в позиции самой молодежи: «молодежи следует проявлять активность», «вникать в суть политической ситуации в стране» (Владивосток, 2020); «пора меняться, а не все сидеть на месте»; «я думаю, молодежи следует проявлять больше требовательности к себе, и это даст толчок к развитию страны» (Мичуринск, 2020). Наряду с повышением уровня политической активности, данная часть моло- 
дежи видит свой вклад в будущность страны в овладении знаниями, чтобы стать квалифицированными специалистами.

Дополнительную информацию о направленности социальной активности молодежи дают ответы на вопрос: «Как вы представляете свое личное будущее? Кем вы ходите стать, где хотите жить и чего добиться в жизни?» В 2019 г. авторы констатировали, что абсолютное большинство студентов так или иначе размышляли на эту тему, и у них сформировалось определенное представление на этот счет, хотя они и признают, что в России тяжело строить планы на будущее.

У большинства планы весьма приземленные - получить хорошие знания, овладеть профессией, устроиться на работу по специальности с достойной заработной платой, заниматься интересным делом, называют конкретную профессию. Но у некоторой части студентов личные планы на будущее сочленяются с общественно значимыми требованиями: «я вижу себя госслужащим, который рушит стереотипы о том, что это зарвавшиеся люди, которые сидят и ничего не делают. Я вижу себя чиновником, который работает на благо общества, который приносит пользу и который создает эффективно функционирующие структуры» (Севастополь); «хочу стать тем, кто будет максимально полезен обществу: если общество живет хорошо, значит, и отдельный индивид живет хорошо» (Ярославль). В 2020 г. ситуация несколько изменилась: стало больше студентов, которые не смогли ответить содержательно на названные выше вопросы. В 2019 г. мы отмечаем, что значительная часть опрошенных студентов заявляют, что готовы жить в России только в том случае, если она станет благополучной страной. В 2020 г. подобного рода высказывания отмечались значительно реже. Есть основания считать, что притягательность Запада, Европы (именно туда были направлены устремления части студентов) на фоне провалов большинства стран Европы в борьбе с пандемией, массовых беспорядков в глазах студентов существенно уменьшилась. В поддержку такого вывода приведем данные ответов на вопрос: «Надо ли нам (России) стремиться к более теплым отношениям с ЕС или предпочтительнее другие варианты?» Целевое назначение вопроса - выявить культурно-цивилизационную составляющую образа России в представлении студентов. Вопрос о цивилизационной принадлежности России вызывает немало споров в научных кругах и среди политиков. В начале второго десятилетия нынешнего века политическое руководство страны склонялось к точке зрения, что Россия - это особая страна, цивилизация, подобно тому, как это принято считать в отношении Китая и Индии. Затем позиция была уточнена: Россия - особая цивилизация, но в рамках общей европейской цивилизации. В 2019 г. нами зафиксировано, что мнения студентов на этот счет противоречивы. Часть из них практически целиком разделяют последнюю позицию, что Россия - особая цивилизация в рамках общеевропейской. «Если говорить в целом о европейском обществе, то Россия, определенно, ее часть. Наверное, большая часть населения может ассоциировать себя с европейским обществом. Однако россияне имеют самобытную историю» (Севастополь).

Другая часть придерживается скорее первой позиции: «Россия - уникальное государство, обладающее огромной территорией, страна развивается по совсем другим направлениям. У нас другая история, другие ценности. ЕС живет своей жизнью, а Россия живет своей жизнью» (Москва).

Резюмируем: представление о будущем страны в студенческой среде противоречиво. Определенная часть студентов не верит в перспективы России, потенциал ее возможности стать передовой, современной страной и готова покинуть страну при первом удобном случае. Другая часть сомневается в перспективах развития России, но надеется как-то приспособиться и жить в такой 
стране, какая она есть и будет. И, наконец, третья часть готова активно участвовать, прилагать максимум собственных усилий для реализации желаемого образа будущего. К сожалению, примененная методика получения эмпирических данных (фокус-групповое интервью), как и любая другая качественная методика, не позволяет точно количественно оценить соотношение групп. Речь может идти только о выявлении тенденции. Она скорее благоприятна: уменьшается численность первой группы и растет третья - те, кто готов верить в будущее страны и готов прилагать усилия для его приближения. И, пожалуй, самое главное: растет число студентов, которые отдают себе отчет в том, что за молодежный проект желаемого будущего России надо бороться. На сегодня в качестве главного метода этой борьбы им видится победа на честных, свободных выборах нового поколения людей. С этим они связывают свои надежды на светлое будущее России.

Статья написана при поддержке РФФИи ЭИСИ № 21-011-31336 «Образ будущего России в представлениях учащейся молодежи: факторы формирования и трансформации в условиях перемен и кризисов».

\title{
Список литературы
}

Иноземцев В. 2018. Несовременная страна: Россия в мире ХХІ века. М.: Алиса Паблишер. 406 с.

Образ будущего России глазами молодежи (под ред. В.С.Комаровского). 2021. М.: Аспект Пресс. 224 с.

Комаровский В.С. 2020. Образ желаемого будущего России: проблемы формирования. - Власть. Т. 28. № 1. С. 45-50.

Семененко И.С. 2021. Дискурсы развития в социальных науках: в преддверии этического переворота. - Полис. Политические исследования. № 2. С. 25-45.

Шестопал Е.Б. 2019. Образ своей страны в сознании граждан как фактор формирования идентичности: политико-психологический аспект. - Траектории политического развитии России: институты, проекты, акторы. М.: Изд-во МГПУ. С. 444-445.

KOMAROVSKY Vladimir Savel'evich, Dr.Sci. (Philos.), Professor of the Institute of Public Administration and Civil Service, Russian Presidential Academy of National Economy and Public Administration (RANEPA) (bld. 1, 84 Vernadskogo Ave, Moscow, Russia, 119571; poiginalb@yandex.ru); Honored Scientist of the Russian Federation

\section{VISION OF THE FUTURE OF THE COUNTRY BY RUSSIAN YOUTH: HOPES AND FEARS}

\begin{abstract}
The article analyzes the students' perception of the desired image of the country in the historically foreseeable perspective of 20-25 years, based on the data of a sociological study. It turns out what is necessary, in the opinion of students, to change in the country so that it can adequately respond to the challenges of our time and take its rightful place among the most advanced countries in the world, and become attractive to young people. The article analyzes the readiness of young people to take a personal part in building a better future, to identify themselves with the country (or, conversely, to leave it at the first opportunity), the role of the country's future image as a society-consolidating (or conflict-generating) factor.
\end{abstract}

Keywords: image of the future, youth, values, identity, consolidation, conflict 